\title{
Secondary Structure of rhBMP-2 in a Protective Biopolymeric Carrier Material
}

\author{
Flora Gilde, ${ }^{\dagger}$ Ofélia Maniti, ${ }^{\dagger}$ Raphael Guillot, ${ }^{\dagger}$ Joao F. Mano, ${ }^{\ddagger}{ }^{\S}$ Delphine Logeart-Avramoglou, ${ }^{\|}$ \\ Frédéric Sailhan," and Catherine Picart* ${ }^{\dagger}$
}

${ }^{\dagger}$ CNRS UMR 5628 (LMGP), Grenoble Institute of Technology and CNRS, 3 parvis Louis Néel, F-38016 Grenoble Cedex, France

${ }^{\ddagger} 3$ B’s Research Group - Biomaterials, Biodegradables and Biomimetics, University of Minho, AvePark, 4806-909, Taipas, Guimarães, Portugal

${ }^{\S}$ ICVS/3B’s - PT Government Associate Laboratory, Braga/Guimarães, Portugal

"Laboratory of Bioengineering and Biomechanics for Bone and Articulations; UMR 7052, CNRS, University Paris Diderot, Sorbonne Paris Cité, 10 avenue de Verdun 75010 Paris, France

\section{Supporting Information}

ABSTRACT: Efficient delivery of growth factors is one of the great challenges of tissue engineering. Polyelectrolyte multilayer films (PEM) made of biopolymers have recently emerged as an interesting carrier for delivering recombinant human bone morphogenetic protein 2 (rhBMP-2 noted here BMP-2) to cells in a matrix-bound manner. We recently showed that PEM made of poly(L-lysine) and hyaluronan (PLL/HA) can retain high and tunable quantities of BMP-2 and can deliver it to cells to induce their differentiation in osteoblasts. Here, we

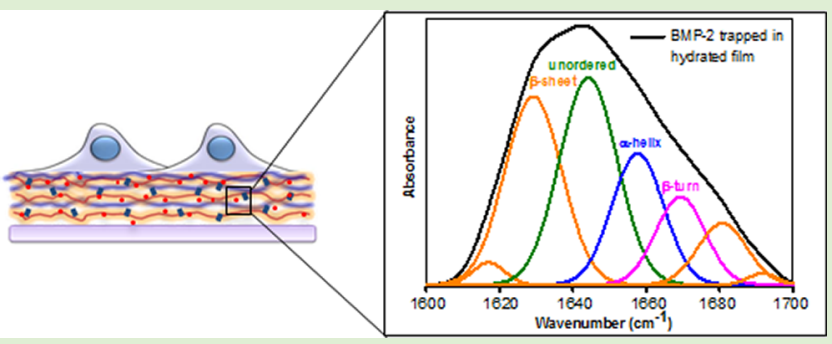
investigate quantitatively by Fourier transform infrared spectroscopy (FTIR) the secondary structure of BMP-2 in solution as well as trapped in a biopolymeric thin film. We reveal that the major structural elements of BMP-2 in solution are intramolecular $\beta$-sheets and unordered structures as well as $\alpha$-helices. Furthermore, we studied the secondary structure of rhBMP-2 trapped in hydrated films and in dry films since drying is an important step for future applications of these bioactive films onto orthopedic biomaterials. We demonstrate that the structural elements were preserved when BMP-2 was trapped in the biopolymeric film in hydrated conditions and, to a lesser extent, in dry state. Importantly, its bioactivity was maintained after drying of the film. Our results appear highly promising for future applications of these films as coatings of biomedical materials, to deliver bioactive proteins while preserving their bioactivity upon storage in dry state.

\section{INTRODUCTION}

Efficient delivery of growth factors is one of the great challenges of tissue engineering. ${ }^{1}$ It is now acknowledged that large doses of potent growth factors, delivered in solution, can lead to severe side effects. ${ }^{2}$ Engineered materials that can regulate the biological presentation of growth factors represent a new class of therapeutic agents for the treatment of a wide variety of diseases. $^{3}$ The ideal carrier would retain and sequester the growth factor locally, thus reducing the dose needed, while enhancing its efficacy. ${ }^{4}$ Importantly, the carrier should preserve the protein bioactivity, which is directly related to its secondary and tertiary structure.

The bone morphogenetic protein (BMP) family is an intensive field of research in its own for tissue engineering applications ${ }^{5}$ as well as for fundamental cell biology studies ${ }^{6}$ due to its physiological importance. BMPs play a crucial role in morphogenesis, tissue patterning and regeneration after tissue damage. ${ }^{7}$ In particular, BMP-2 is a highly potent morphogen that induces muscle precursors and mesenchymal stem cell differentiation in bone cells. ${ }^{8}$ Currently, BMP-2 is used in clinics, ${ }^{9}$ and the only approved formulation of BMP-2 uses an absorbable collagen sponge as a carrier agent. However, up to $12 \mathrm{mg}$ (much higher dose than physiological concentrations) is used, thus raising serious concerns about its safety as reported in the recent literature. ${ }^{10}$ Other carrier biomaterials have been and are currently being developed. ${ }^{5,11}$ Mimics of the natural extracellular matrix, including fibrin films, ${ }^{12}$ hyaluronan hydrogels, ${ }^{13}$ and polypeptide and polysaccharide-based layer-by-layer films ${ }^{14,15}$ appear particularly interesting due to their natural composition. Natural biopolymers may not only permit the protein from being presented in a "matrix-bound" manner, but they also provide a water-rich environment. This may be a crucial point for preserving the stability of the proteins in the dry state once loaded in the biopolymeric coatings. In fact, dehydration is known to possibly greatly impact proteins structures. ${ }^{16}$ The drying process removes part of the hydration

Received: July 12, 2012

Revised: August 30, 2012

Published: September 11, 2012 
layer, which may disrupt the native state of a protein and cause protein aggregation. ${ }^{16}$ It is known that protein conformation is very often lost upon storage in dry conditions, unless stabilizers such as sugars, polyols, or polyaminoacids are added during the freeze-drying process. ${ }^{16}$ Very recently, atomistic molecular dynamics simulations ${ }^{17}$ suggested that the environment (vacuum versus water) is a key factor in the stabilization of the secondary and tertiary structure of BMP-2. Friess and coworkers have shown that controlled precipitation of BMP-2 proteins from highly concentrated solutions $(20 \mathrm{mg} / \mathrm{mL})$ lead to the formation of microparticles of micrometer size ( 7 and 35 $\mu \mathrm{m}$ bimodal distribution). ${ }^{18}$ They used Fourier transform infrared (FTIR) spectroscopy to show that the structure of BMP-2 in the precipitated state and after resolubilization in an acidic buffer was similar to that of the protein in solution. ${ }^{19}$ They evidenced the formation of mainly $\beta$-sheet structures and $\alpha$-helices. The formation of $\beta$-sheets was also observed by circular dichroism. ${ }^{20}$

However, quantitative information on BMP-2 secondary structure in solution or in a carrier material is still lacking. Here, we quantitatively investigated by FTIR the secondary structure of BMP-2 in solution as well as trapped in a nanostructured biopolymeric thin film. The film is a polyelectrolyte multilayer film made of poly(L-lysine) and hyaluronan (PLL/HA), which was recently shown to retain high and tunable quantities of rhBMP-2 and to deliver it to cells in a "matrix-bound" manner. ${ }^{15,21}$ FTIR was chosen as it is a powerful technique to qualitatively and quantitatively assess protein secondary structure $^{22-24}$ and to obtain the relative amount of different types of secondary structures based on the band areas. ${ }^{25-27}$ It is a very precise $\left(<2 \mathrm{~cm}^{-1}\right)$, sensitive, and reproducible technique $^{28,29}$ that is indeed routinely used to assess the secondary structure of therapeutic proteins.

\section{MATERIALS AND METHODS}

Materials. PLL hydrobromide (P2626, $6.8 \times 10^{4} \mathrm{~g} / \mathrm{mol}$ ) was purchased from Sigma (St-Quentin Fallavier, France), and HA $(3.6 \times$ $10^{5} \mathrm{~g} / \mathrm{mol}$ ) was obtained from Lifecore Biomedical (USA). They were dissolved at $0.5 \mathrm{mg} / \mathrm{mL}$ and $1 \mathrm{mg} / \mathrm{mL}$, respectively, in a buffered saline (0.15 M NaCl, $20 \mathrm{mM}$ HEPES, pH 7.4, called hereafter HEPES$\mathrm{NaCl}$ buffer). For film cross-linking, 1-ethyl-3-[3dimethylaminopropyl]carbodiimide hydrochloride (EDC, Sigma, St Quentin Fallavier, France) was mixed with a $N$-hydroxysulfosuccinimide (sulfo-NHS, Chemrio, China) in $0.15 \mathrm{M} \mathrm{NaCl}$ solution ( $\mathrm{pH} 5.5$ ) at concentrations of $30 \mathrm{mg} / \mathrm{mL}$ and $11 \mathrm{mg} / \mathrm{mL}$, respectively. BMP-2 was from Medtronic Biopharma BV.

Quantitative Analysis by FTIR Spectroscopy. A Vertex 70 spectrophotometer (Bruker Optics Gmbh, Ettlingen, Germany) was used for the acquisition of FTIR spectra. Single-channel spectra were recorded between 400 and $4000 \mathrm{~cm}^{-1}$ with a $2 \mathrm{~cm}^{-1}$ resolution by means of the OPUS Software v6.5 (Bruker). A nitrogen-cooled mercury-cadmium-telluride (MCT) detector was used to improve the detection level. Such detector is known to produce a noise level 10-50 times lower than other detectors. ${ }^{29}$ Different accessories were used depending on the experiments: an Aquaspec transmission cell for studying BMP-2 in solution, an attenuated total reflection (ATR) liquid cell for the study of BMP-2 loaded in hydrated films, and a standard transmission accessory for the study of the BMP-2 loaded films deposited on silicon substrates and subsequently dried. All these accessories were purchased from Bruker Optics.

The OPUS Software v6.5 (Bruker $\mathrm{GmbH}$ ) was used for the treatment and deconvolution of the spectra. Residual water and $\mathrm{CO}_{2}$ contributions were removed, and baseline correction was done manually, choosing always the same reference points in each group of spectra. When residual noise due to water (especially in dry conditions) was still present, the spectra were smoothened using a specific algorithm from Opus software. The frequencies of the different components forming the amide I band were first determined by calculating of the second derivative of the Fourier smoothed spectrum. ${ }^{25,27}$ There was thus no arbitrary decomposition into a preset number of bands and on the peak position. Once the number of component bands was determined, the amide I band was fitted by using the component frequency, width, and intensity as fitting parameters. The more consistent results were obtained when all component peaks were assumed to be Gaussian. The correspondence of each component band with a given secondary structure was established by comparing the frequency of its maximum to the value given in the literature. ${ }^{30}$ We defined the relative contribution of each component (in \%) by the ratio of the area of each peak over the area of the total amide I band. ${ }^{27}$

Characterization of BMP-2 Secondary Structure in Solution. First, the BMP-2 solution was purified. To this end, it was first precipitated using a $10 \%$ ammonium sulfate (AS) solution. ${ }^{31}$ The mixture was centrifuged at $13000 \mathrm{rpm}$ for $10 \mathrm{~min}$ after which the supernatant was removed. This procedure was repeated three times with a $2 \%$ AS solution. Finally, the protein was resuspended in the 1 $\mathrm{mM} \mathrm{HCl}$ in $\mathrm{D}_{2} \mathrm{O}(\mathrm{pH}=3)$ solution or in the HEPES-NaCl buffer in $\mathrm{D}_{2} \mathrm{O}(\mathrm{pH}=7.4)$. The final protein concentration was $\sim 2 \mathrm{mg} / \mathrm{mL}$ for rhBMP-2 in $1 \mathrm{mM} \mathrm{HCl}(\mathrm{pH} 3)$. At $\mathrm{pH} 7.4$, the protein is known to be less soluble. ${ }^{20,32,33}$ We estimated the BMP-2 concentration of the resuspended solution to be $400 \mu \mathrm{g} / \mathrm{mL}$ at this $\mathrm{pH}$, based on the difference of the maximum absorbance of the protein. Sixty microliters of BMP-2 was injected in the Aquaspec cell, and a single-channel spectrum of 64 interferograms was recorded.

PLL/HA Film Characterization by FTIR. The buildup of PLL/ HA films in HEPES-NaCl buffer was followed by FTIR spectroscopy as previously described. ${ }^{34}$ For studies in hydrated conditions, $\mathrm{D}_{2} \mathrm{O}$ was used as solvent instead of water in order to avoid the overlapping water band in the amide I region $(\mathrm{O}-\mathrm{H}$ bending vibration at 1643 $\mathrm{cm}^{-1}$ versus $\mathrm{O}-\mathrm{D}$ bending vibration at $\left.1209 \mathrm{~cm}^{-1}\right)$. The spectra of hydrated (PLL/HA) 12 films were acquired in situ using ATR mode. To this end, films were built and cross-linked on a ZnSe crystal, and a single-channel spectrum of 64 interferograms was recorded. For studies in dry conditions, films were built as described previously ${ }^{35}$ on a $\sim 1 \mathrm{~cm}^{2}$ silicon substrate (Siltronix, France) using HEPES-NaCl (dissolved in $\mathrm{H}_{2} \mathrm{O}$ ) followed by cross-linking. The films were then rinsed with milli-Q water to remove the salt and dried for $1 \mathrm{~h}$ at $37^{\circ} \mathrm{C}$. The film spectra in transmission were acquired by summing 256 interferograms. For long-term stability measurements, the films were stored in the dry state at $4{ }^{\circ} \mathrm{C}$. Before each FTIR acquisition, they were incubated for $1 \mathrm{~h}$ at $37^{\circ} \mathrm{C}$.

Characterization of BMP-2 Secondary Structure in Hydrated and in Dry PLL/HA Films. For BMP-2 trapped in hydrated (PLL/ $\mathrm{HA})_{12}$ films built in $\mathrm{D}_{2} \mathrm{O}, \mathrm{BMP}-2$ was loaded from a solution at 100 $\mu \mathrm{g} / \mathrm{mL}$ in $1 \mathrm{mM} \mathrm{HCl}$ in $\mathrm{D}_{2} \mathrm{O}(\mathrm{pH}=3)$ following the protocol established previously. ${ }^{15}$ The rinsing steps were done with HEPES$\mathrm{NaCl}$ buffer. The spectrum of BMP-2 was obtained by subtracting the spectrum of the film in contact with the HEPES-NaCl buffer to that of the BMP-2-loaded film (measured in the same buffer after rinsing of the film).

For study of BMP-2 in dry films, BMP-2 in $1 \mathrm{mM} \mathrm{HCl}\left(\right.$ in $\left.\mathrm{H}_{2} \mathrm{O}\right)$ was loaded in the PLL/HA film prepared in the HEPES-NaCl buffer (in $\mathrm{H}_{2} \mathrm{O}$ ) and dried as described above for the film. The spectrum of BMP-2 inside dry films was obtained by calculating the difference between the average spectrum of two independent BMP-2 loaded films and the average spectrum of two control samples (i.e., films that have followed the same procedure, except that BMP-2 was not present in the loading solution).

C2C12 Cell Culture and Alkaline Phosphatase Activity Test (ALP Test). Murine $\mathrm{C} 2 \mathrm{C} 12$ skeletal myoblasts ( $<25$ passages, obtained from the American Type Culture Collection, ATCC) were cultured in tissue culture Petri dishes, in a 1:1 Dulbecco's modified Eagle medium (DMEM)/Ham's F12 medium (Gibco, Invitrogen, France) mixture supplemented with $10 \%$ fetal bovine serum (FBS, PAA Laboratories, France), $100 \mathrm{U} / \mathrm{mL}$ penicillin $\mathrm{G}$, and $100 \mu \mathrm{g} / \mathrm{mL}$ streptomycin (Gibco, Invitrogen, France) in a $37{ }^{\circ} \mathrm{C}, 5 \% \mathrm{CO}_{2}$ 

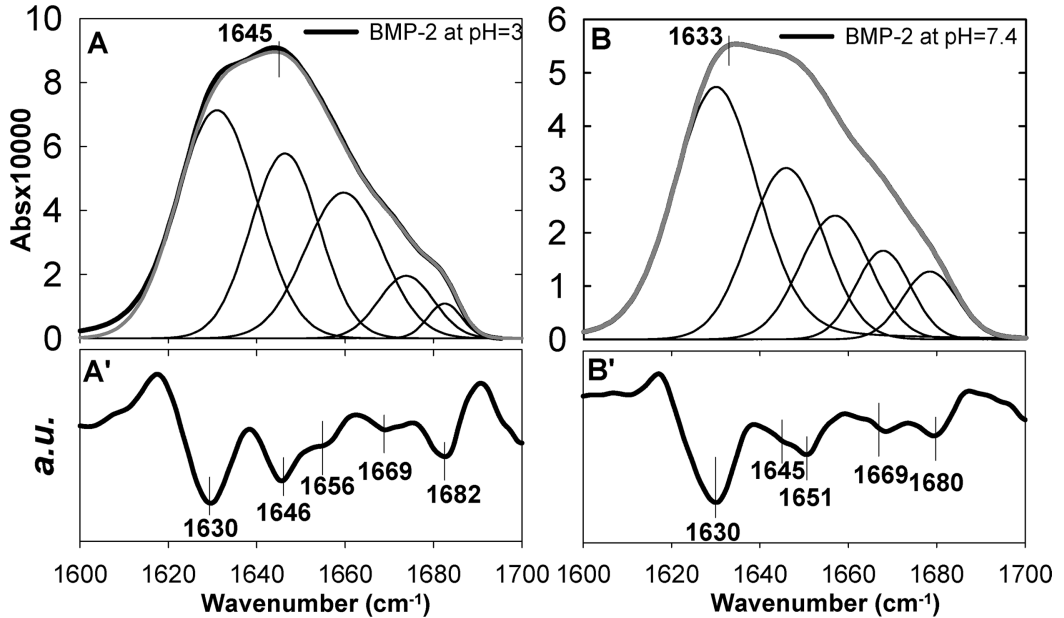

Figure 1. FTIR spectra and corresponding second derivatives of rhBMP-2 in solution at $\mathrm{pH} 3\left(\mathrm{~A}, \mathrm{~A}^{\prime}\right)$ and at pH 7.4 (B, $\left.\mathrm{B}^{\prime}\right)$ (black: experimental spectrum; gray: fitted spectrum). Measurements were performed in $\mathrm{D}_{2} \mathrm{O}$.

Table 1. Results of the Deconvolution of the FTIR spectra of rhBMP-2 in Solution at pH 3 (No Salt) or at pH 7.4 (HEPES$\mathrm{NaCl}$ Buffer) as Well as in Hydrated or Dry Polyelectrolyte Multilayer Films ${ }^{a}$

\begin{tabular}{|c|c|c|c|c|c|c|c|c|}
\hline & LW inter. $\beta$-sheet & $\mathrm{LW}$ intra. $\beta$-sheet & unordered & $\alpha$-helix & $\beta$-turn & HW intra. $\beta$-sheet & HW inter. $\beta$-sheet & \\
\hline \multirow{2}{*}{ BMP-2 in solution $\mathrm{pH} 3$} & & 1631 & 1646 & 1660 & 1674 & 1683 & & $\mathrm{~W}$ \\
\hline & & 39 & 27 & 24 & 7 & 3 & & $\%$ \\
\hline \multirow[t]{2}{*}{ BMP-2 in solution Hepes- $\mathrm{NaCl}$ pH 7.4} & & 1630 & 1646 & 1657 & 1668 & 1678 & & $\mathrm{~W}$ \\
\hline & & 44 & 24 & 16 & 9 & 7 & & $\%$ \\
\hline \multirow[t]{2}{*}{ BMP-2 trapped in hydrated film } & 1617 & 1630 & 1644 & 1658 & 1670 & 1680 & 1690 & $\mathrm{~W}$ \\
\hline & 2 & 28 & 31 & 18 & 11 & 8 & 1 & $\%$ \\
\hline \multirow[t]{2}{*}{ BMP-2 trapped in dry film } & 1628 & 1638 & 1652 & 1664 & 1678 & 1689 & 1694 & $\mathrm{~W}$ \\
\hline & 2 & 21 & 34 & 21 & 16 & 5 & 1 & $\%$ \\
\hline
\end{tabular}

${ }^{a}$ LW/HW: Low/High Wavenumber; W: Wavenumber $\left(\mathrm{cm}^{-1}\right)$; \%: percentage relative to the total amide I band integral.

incubator. Cells were subcultured prior to reaching $60-70 \%$ confluence (approximately every 2 days).

The bioactivity of BMP-2 on $\mathrm{C} 2 \mathrm{C} 12$ cells was determined by assaying the ALP activity, a marker of osteogenic differentiation, as previously described. ${ }^{15} \mathrm{C} 2 \mathrm{C} 12$ cells were seeded in 24-well plates (90 000 cells per well) in $1 \mathrm{~mL}$ of growth medium. After 3 days of culture, the culture medium was removed, and the cells were washed with PBS and lysed by sonication ( $5 \mathrm{~s}$ ) in $500 \mu \mathrm{L}$ of $0.1 \%$ Triton-X100 in PBS. $180 \mu \mathrm{L}$ of a buffer containing $0.1 \mathrm{M}$ 2-amino-2-methyl-L-propanol (Sigma, France), $1 \mathrm{mM} \mathrm{MgCl}$, and $9 \mathrm{mM}$ p-nitrophenyl phosphate (Euromedex, France) adjusted to $\mathrm{pH} 10$ was added to $20 \mu \mathrm{L}$ of lysate. The enzymatic reaction was monitored in a $96-$ well plate by measuring the absorbance at $405 \mathrm{~nm}$ using a TECAN Infinite 1000 microplate reader (Tecan, Austria) over $10 \mathrm{~min}$. The total protein content of each sample was determined using a bicinchoninic acid-based protein assay kit (Interchim, France). The ALP activity was expressed as mmoles of p-nitrophenol produced per minute per milligram of protein (pnp/ $\mathrm{min} / \mathrm{mg}$ ).

The bioactivity of loaded BMP-2 was also assessed after drying the film and upon storage at $4{ }^{\circ} \mathrm{C}$. To this end, the samples were loaded with BMP-2 as previously described and thoroughly washed in HEPES-NaCl buffer then in ultrapure water. They were air-dried for 2 $\mathrm{h}$ under a laminar flow hood and stored at $4{ }^{\circ} \mathrm{C}$. The BMP-2 activity was determined right after this drying step and after 1 month of storage. The samples were rehydrated $30 \mathrm{~min}$ in the HEPES-NaCl buffer and sterilized under UV irradiation before depositing cells. The ALP activity test was performed after 3 days of culture.

\section{RESULTS AND DISCUSSION}

Secondary Structure of BMP-2 in Solution at Acidic and at Neutral pH. The secondary structure of BMP-2 protein was first investigated by FTIR in solution (Figure 1) with a focus on the Amide I band. $\mathrm{pH} 3$ was selected as it corresponds to its maximum solubility ${ }^{36}$ and to the recommended conditions of storage. Indeed, we have previously shown that loading of BMP-2 in the biopolymeric film at $\mathrm{pH} 3$ was optimum in terms of homogeneity and loaded amount. ${ }^{15}$ Physiological conditions $(0.15 \mathrm{M} \mathrm{NaCl}, \mathrm{pH} 7.4$, Figure 1B), which correspond to the conditions of film buildup and cell culture experiments, were also studied. Second derivatives of the spectra were also calculated (Figure $\left.1 \mathrm{~A}^{\prime}, \mathrm{B}^{\prime}\right)$. Based on these second derivatives, on FTIR data on proteins, ${ }^{30}$ and on a previous study on precipitated BMP-2 microparticles, ${ }^{19}$ the five observed minima were attributed to four different types of secondary structures as follows: $\sim 1630$ $\mathrm{cm}^{-1}$ and $\sim 1680 \mathrm{~cm}^{-1}$ to antiparallel $\beta$-sheets (two contributions at low and high wavenumbers, LW and HW, respectively), $1645 \mathrm{~cm}^{-1}$ to unordered, $\sim 1651-1657 \mathrm{~cm}^{-1}$ to $\alpha$-helix, and $\sim 1670 \mathrm{~cm}^{-1}$ to $\beta$-turn structures. ${ }^{30}$

At first sight, the spectra of BMP-2 at different $\mathrm{pHs}$ appeared to differ as its maximum was positioned at $1645 \mathrm{~cm}^{-1}$ for BMP2 at $\mathrm{pH} 3$, whereas it was at $1633 \mathrm{~cm}^{-1}$ for BMP-2 at $\mathrm{pH} 7.4$ in the presence of salt. Decomposition of the amide I band allowed the quantification of the respective contributions of each type of secondary structure (Table 1).

Independent experiments indicated that the precision of the peak position obtained by fitting the spectra is $<2 \mathrm{~cm}^{-1}$. The precision on the $\%$ of secondary structures can be estimated at $\sim 3$ to $4 \%$ for the most prominent peaks and highest peaks and $\sim 1-2 \%$ for the smallest ones. 
First, we noticed that the highest contribution was that of antiparallel $\beta$-sheets (sum of LW and HW $\beta$-sheet), which accounted for $42 \%$ of the structure at $\mathrm{pH} 3$ and $51 \%$ at $\mathrm{pH} 7.4$ in the presence of salt. The $\alpha$-helix contribution represented $24 \%$ of the secondary structure at $\mathrm{pH} 3$ and only $16 \%$ at $\mathrm{pH}$ 7.4. Of note, the percent of unordered structures remained unchanged $(\sim 24-27 \%)$ under both conditions, and the percent of $\beta$-turn was also similar $(\sim 7-9 \%)$. Thus, the formation of $\beta$-sheet structures was induced by the increase of $\mathrm{pH}$ closer to its isoelectric point $\left(8.5^{37}\right)$, where BMP-2 is less soluble. $^{32}$

These experimental determinations of the percent of secondary structures were indeed relatively close to the values deduced from the crystal structure of BMP- $2^{38}$ and from molecular dynamics simulations of BMP-2 structure in water. ${ }^{17}$ These latter values range from 41 to $52 \%$ for $\beta$-sheets and from 8 to $12 \%$ for $\alpha$-helix structures. Experimental data obtained by circular dichroism also indicated the prominence of $\beta$-sheets. ${ }^{20}$ In addition, FTIR data on native BMP-2 at very high concentration $(20 \mathrm{mg} / \mathrm{mL})$ and on dried microparticles of BMP-2 showed that $\beta$-sheets represented $\sim 25 \%$ of the secondary structural elements. ${ }^{18}$ Thus, although performed in different experimental conditions, our data are consistent with these previous experimental and theoretical studies.

Secondary Structure of PLL/HA Films. Next, we investigated the structure of the polyelectrolyte multilayer film that was used as a reservoir for BMP-2 storage in the hydrated and dry states. This analysis was important to obtain information on the possible changes in the film structure. We studied the amide I region in different solvents $\left(D_{2} \mathrm{O}\right.$ versus $\mathrm{H}_{2} \mathrm{O}$ ) and in hydrated or dry conditions.

Figure 2 shows the typical infrared spectra of cross-linked $(\mathrm{PLL} / \mathrm{HA})_{12}$ films in hydrated and dry states with a focus on the amide I and amide II bands. The spectrum of the hydrated film is shown for films built in $\mathrm{D}_{2} \mathrm{O}$ and in $\mathrm{H}_{2} \mathrm{O}$. The spectrum

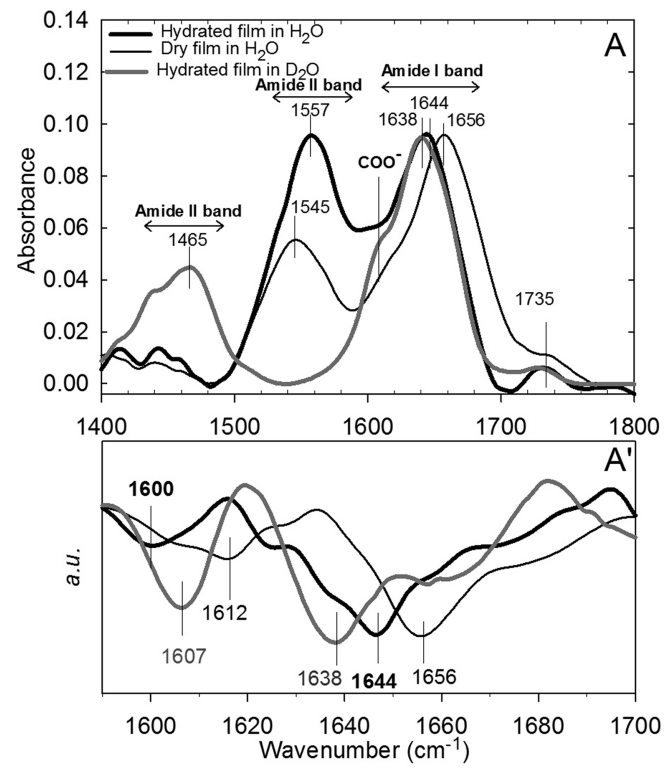

Figure 2. FTIR spectrum (A) and second derivative of the spectrum $\left(\mathrm{A}^{\prime}\right)$ of (PLL/HA $)_{12}$ film in hydrated and dry states: hydrated film in $\mathrm{D}_{2} \mathrm{O}$ (thick black line); hydrated film in $\mathrm{H}_{2} \mathrm{O}$ (thick gray line); dry film (thin line). For the sake of comparison, the spectrum of the dry film was multiplied by 2 . of dry film was obtained after drying a film prepared in HEPES$\mathrm{NaCl}$ buffer in $\mathrm{H}_{2} \mathrm{O}$.

Table 2. Position of the Main Peak of the Amide I Band for PLL/HA Films Built in HEPES-NaCl in $\mathrm{D}_{2} \mathrm{O}, \mathrm{H}_{2} \mathrm{O}$, and after Drying a Film Built in $\mathrm{H}_{2} \mathrm{O}$

\begin{tabular}{lllc} 
& $\mathrm{D}_{2} \mathrm{O}$ & $\mathrm{H}_{2} \mathrm{O}$ & dry \\
amide I main peak & 1638 & 1644 & 1656 \\
$\mathrm{COO}^{-}$ & 1607 & 1600 & 1612 \\
\hline
\end{tabular}

The comparison between the spectra for hydrated films obtained in $\mathrm{D}_{2} \mathrm{O}$ and in $\mathrm{H}_{2} \mathrm{O}$ revealed some differences. The most significant change was the shift of the entire amide II band from $1557 \mathrm{~cm}^{-1}$ (maximum of this band) to $1465 \mathrm{~cm}^{-1}$ when the film was built in a $\mathrm{D}_{2} \mathrm{O}$. This shift can be justified by the hydrogen/deuterium exchange as reported previously in the literature. ${ }^{39}$ In (PLL/HA) films, the amide I band is mainly representative of the PLL structure. ${ }^{40}$ The second derivatives allow one to determine the position of the major peak of the amide I band (Figure 2A'). A strong minimum was visible at $1638 \mathrm{~cm}^{-1}$ for the film built in $\mathrm{D}_{2} \mathrm{O}$, at $1644 \mathrm{~cm}^{-1}$ for that built in $\mathrm{H}_{2} \mathrm{O}$, and at $1656 \mathrm{~cm}^{-1}$ for the dry film, which could be attributed to unordered structures. ${ }^{40,41}$ Thus there was a significant shift toward higher wavenumbers especially for the dry film $\left(+12 \mathrm{~cm}^{-1}\right.$ after drying the film built in water). This total shift is due to the combined effect of solvent exchange and subsequent drying, ${ }^{39}$ as the film was built in $\mathrm{D}_{2} \mathrm{O}$ for studies in hydrated conditions versus $\mathrm{H}_{2} \mathrm{O}$ for studies on dry and stored films. A weaker contribution, attributed to turn structures, was observed at 1663 and $1674 \mathrm{~cm}^{-1}$ for hydrated films and at 1680 $\mathrm{cm}^{-1}$ for dry films. The $\mathrm{COO}^{-}$contribution was also shifted from $\sim 1600 \mathrm{~cm}^{-1}$ in $\mathrm{H}_{2} \mathrm{O}$ to $1607 \mathrm{~cm}^{-1}$ in $\mathrm{D}_{2} \mathrm{O}$ and $\sim 1612$ $\mathrm{cm}^{-1}$ for dry films. A small contribution of $\mathrm{COOH}$ of $\mathrm{HA}$ was also visible at $\sim 1735 \mathrm{~cm}^{-1}$.

After peak decomposition (Supporting Information, Figure SI1), we found that $\sim 90-95 \%$ of the structural elements in PLL/HA hydrated or dry films were unordered structures and that only 5-10\% were turn structures. We thus conclude that the hydrated PLL/HA film exhibited mostly an unordered structure, which was maintained after drying the film.

Structure of BMP-2 Trapped in Hydrated or Dry PLL/ HA Films. The structure of BMP-2 trapped in hydrated or dry (PLL/HA) films was subsequently investigated (Figure 3 ). In this case, some interactions between the protein and the film might occur, as BMP-2 has a very strong affinity for the film and remained trapped in it even after extensive washing. ${ }^{15}$ In a previous study, we have quantified the amount of adsorbed BMP-2 that is trapped after thorough rinsing of the film ${ }^{15}$ as a function of the concentration of the BMP-2 solution used for the loading and as a function of film thickness. For an initial BMP-2 concentration in solution of $100 \mu \mathrm{g} / \mathrm{mL}$ (used here for its loading in the film), this amount was estimated to be of 769 $\pm 69 \mathrm{ng} / \mathrm{cm}^{2} .15$

For BMP-2 in hydrated films, we noted at first sight that the absorbance was maximal at $\sim 1644 \mathrm{~cm}^{-1}$, showing similarities with that of BMP-2 in solution at $\mathrm{pH} 3$ (Figure 1A). However, besides the five contributions already observed for BMP-2 in solution, two new but very small contributions appeared at LW $\left(\sim 1615,1628 \mathrm{~cm}^{-1}\right)$ and HW $\left(\sim 1691 \mathrm{~cm}^{-1}\right)$ for BMP-2 in films, as compared to BMP-2 in solution (Figure 1). They can unambiguously be attributed to intermolecular $\beta$-sheet structures, ${ }^{30}$ which may result from either protein-protein 

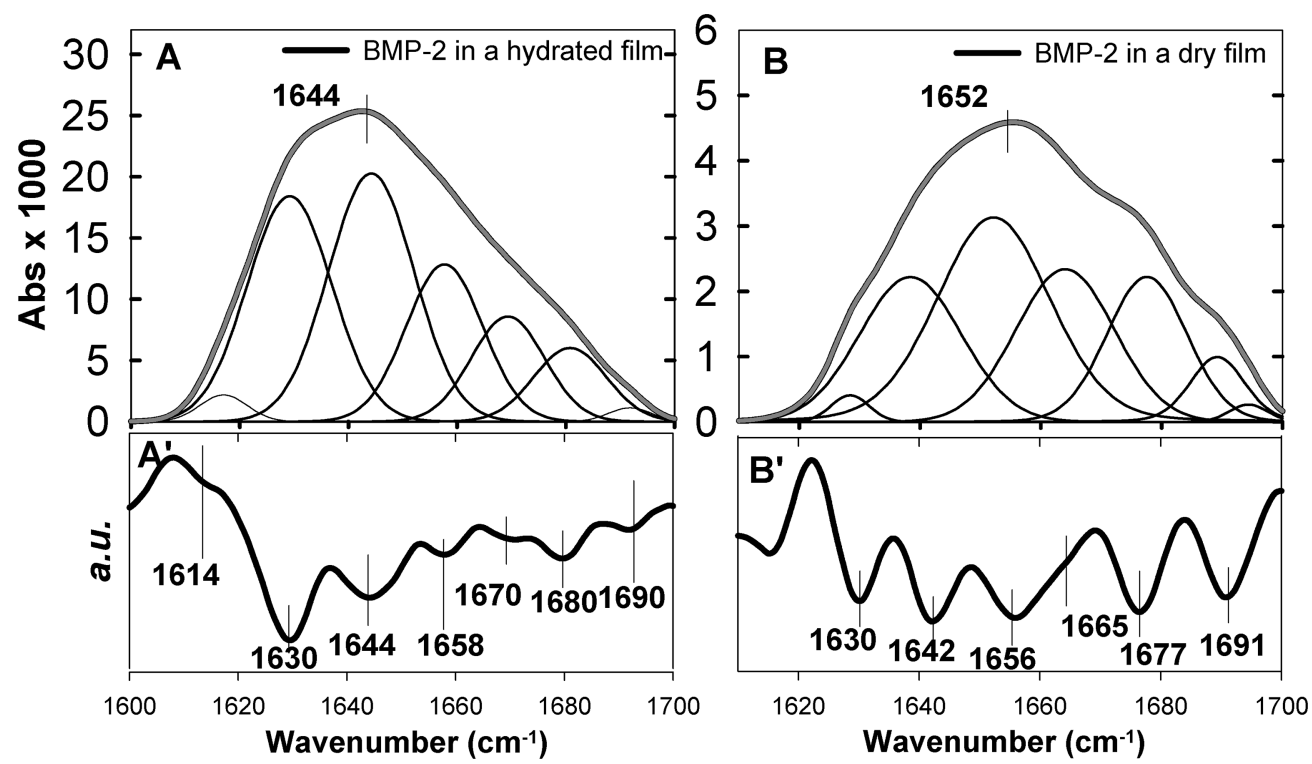

Figure 3. FTIR spectra and second derivative of BMP-2 trapped in cross-linked (PLL/HA) ${ }_{12}$ films $\left(\mathrm{A}, \mathrm{A}^{\prime}\right)$ in a $\mathrm{HEPES}-\mathrm{NaCl}$ buffer at $\mathrm{pH} 7.4$ (hydrated film) and $\left(\mathrm{B}, \mathrm{B}^{\prime}\right)$ after drying the film (black: experimental spectrum; gray: fitted spectrum).

interactions or from protein-polyelectrolyte interactions. All the other peak positions present in the second derivatives were close to those previously observed for the protein in solution. We also performed control experiments to ensure that the contribution of the film to the BMP-2 spectrum was negligible. To this end, the film was subjected to the same sequence of dipping as for BMP-2, except that BMP-2 was not added (Figure SI2). A very small decrease in the $1600-1700 \mathrm{~cm}^{-1}$ region of 0.001 absorbance units, which is 25 times smaller than the BMP-2 signal measured in the amide I band region (Figure $3 \mathrm{~A})$. Indeed, a positive absorbance was measured for BMP-2 in the amide I band region.

The deconvolution of the spectrum (Table 1) led to the most consistent results so far considering seven peaks. BMP-2 in hydrated films mostly formed intramolecular $\beta$-sheets (36\%), unordered structures (31\%), $\alpha$-helix (18\%), $\beta$-turn (11\%), and only a very minor fraction of intermolecular $\beta$-sheets (3\%). Indeed, the percentages of the different types of secondary structures differed by only few percent from those of BMP-2 in solution at $\mathrm{pH}$ 3. Thus, although BMP-2 was physically confined in the film, its structure remained close to the one it had in solution at $\mathrm{pH} 3$.

At first glance, the spectrum of BMP-2 trapped in a dry film (Figure 3B) was different when compared to all other conditions (BMP-2 in hydrated film or in solution at different $\mathrm{pHs)}$. The maximum of the spectrum was shifted to a higher wavenumber at $1652 \mathrm{~cm}^{-1}$. This shift of $\sim 8 \mathrm{~cm}^{-1}$ is reminiscent of the shift observed for PLL/HA films built in the HEPES$\mathrm{Nacl}$ buffer (in $\mathrm{H}_{2} \mathrm{O}$ ) and dried (Figure 2). It may thus be due to the different experimental conditions used, notably, (i) BMP-2 loading in water and not in $\mathrm{D}_{2} \mathrm{O}$, which was used for the in situ experiments in hydrated films and (ii) drying of the BMP-2 loaded film, which restricts the mobility of the polymeric and polypeptidic chains. Furthermore, the two minima previously observed at 1670 and $1680 \mathrm{~cm}^{-1}$ were replaced by a single but more pronounced minimum at 1677 $\mathrm{cm}^{-1}$, which renders the distinction between $\beta$-turn and intramolecular $\beta$-sheets more difficult. By considering the systematic shift in the peak positions and by still considering seven contributions, which gave the best fits, we found that
BMP-2 in dry films formed unordered structures (34\%), intramolecular $\beta$-sheets (26\%), $\alpha$-helix (21\%), $\beta$-turn (16\%), and intermolecular $\beta$-sheets (3\%). The most important differences with BMP-2 in hydrated films arose from the decrease in intramolecular $\beta$-sheets and the concomitant increase in unordered and $\beta$-turn structures.

Thus, FTIR revealed the predominance of $\beta$-sheets and unordered structures on BMP-2 trapped in hydrated films and in dry films as well. The fraction of intramolecular $\beta$-sheets decreased from 42 to $51 \%$ for BMP-2 in solution to $25-36 \%$ for BMP-2 in films, the strongest decrease being observed for BMP-2 in dry films. The \% of unordered structures in trapped BMP-2 was higher (31-34\%) for BMP-2 in films as compared to its solution counterpart (24-27\%). The presence of $\alpha$-helix was also confirmed, with an overall percentage of $16-24 \%$.

Bioactivity of "Matrix-Bound" BMP-2 in Dry Films. An important question is whether the bioactivity of matrix-bound BMP-2 was maintained in dry films, as we already know from our previous studies that BMP-2 loaded in hydrated films is bioactive. ${ }^{15}$ In order to assess the bioactivity of BMP-2, we chose $\mathrm{C} 2 \mathrm{C} 12$ myoblast cells as a working model. These cells constitute an acknowledged in vitro model system to study the ability of BMPs to alter cell lineage from the myogenic to the osteogenic phenotype, ${ }^{42}$ as BMP-2 induced the expression of ALP. In a previous study, we have already demonstrated that BMP-2 presented in a matrix-bound manner from hydrated $\mathrm{PLL} / \mathrm{HA}$ films induced osteoblastic differentiation of $\mathrm{C} 2 \mathrm{C} 12$ myoblasts. ${ }^{15}$ Here, the bioactivity of the films was tested either right after their preparation, i.e., in hydrated state, or after drying of the film for a short period $(2 \mathrm{~h})$ or after storage of the film in dry conditions for one month. First, we verified by FTIR that the films could be stored in the dry state for this time period (Supporting Information Figure SI3). Only very minor changes of less than $6 \%$ were noticed in the FTIR spectra, especially in the $\mathrm{COO}^{-}$peak region and in the amide I band. The ALP test was performed on $\mathrm{C} 2 \mathrm{C} 12$ myoblasts after 3 days of contact with the BMP-2 loaded films (Figure 4). A control value for the bioactivity of BMP-2 in solution (i.e., added to the cell culture medium for 3 days) was also obtained in conditions 


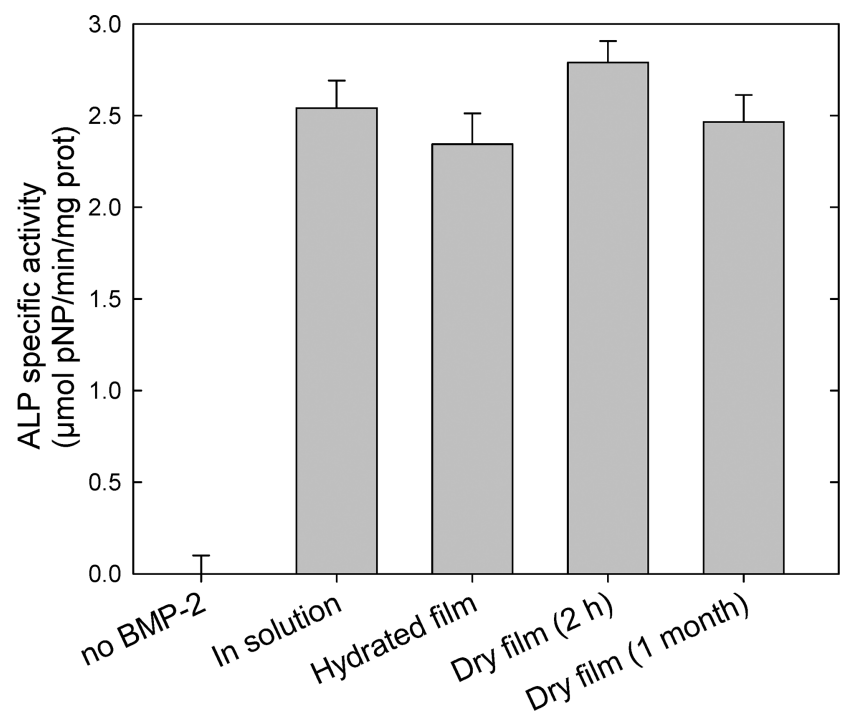

Figure 4. Quantification of ALP activity of $\mathrm{C} 2 \mathrm{C} 12$ cells cultured for 3 days in the presence of BMP-2 in solution at $200 \mathrm{ng} / \mathrm{mL}$ (control value for BMP-2 bioactivity) or on the (PLL/HA) films loaded or not loaded with BMP-2. Films were either hydrated or dried for $2 \mathrm{~h}$, or dried and subsequently stored for a month. There was no statistical difference between the conditions, except for the condition without BMP-2 in the film. Error bars are standard error of the mean (SEM).

where the bioactivity has reached a plateau value ${ }^{15}$ (ie for a BMP-2 concentration of $200 \mathrm{ng} / \mathrm{mL}$ ).

Very interestingly, the BMP-2 loaded PLL/HA films dried for $2 \mathrm{~h}$ or dried and stored for 1 month retained a full activity, similar to that of hydrated films and to the plateau value obtained for BMP-2 in solution. It is difficult to precisely quantify the fraction of BMP-2 that is bioactive in the hydrated film, which remained bioactive after drying of the film. However, a rough estimate can be made, considering the fact that the ALP response is proportional to the amount of BMP-2 loaded in the films ${ }^{15}$ and that a plateau value in the ALP signal was observed for a BMP- 2 concentration in the film of $\sim 400$ $\mathrm{ng} / \mathrm{cm}^{2}{ }^{15}$ As the effective BMP-2 loaded concentration in the film was previously determined to be $\sim 770 \mathrm{ng} / \mathrm{cm}^{2}$ in our experimental conditions, ${ }^{15}$ one can infer that at least $52 \%$ of BMP-2 was bioactive. Thus, although there was a slight increase in unordered structures upon drying of the BMP-2 loaded film, the overall activity of the protein was still very high after rehydration of the film. The presence of a large number of $\mathrm{H}$ bond in the (PLL/HA) films ${ }^{40}$ and a large number of water molecules around HA, even in the dry state, ${ }^{43}$ are probably playing an important role in this process. Importantly, the protein is trapped in the film, but the structure of the film allowed it to retain a large fraction of intramolecular $\beta$-sheets and to maintain its central $\alpha$-helix. In analogy to sugars that are widely used as stabilizing agents during drying of proteins, ${ }^{44}$ the biopolymeric film plays the role of stabilizer, or protective carrier, for the protein.

In conclusion, BMP-2 trapped in hydrated and dry PLL/HA films retained its overall secondary structure, but an increase in unordered structures and a decrease of $\beta$ sheets was noted as compared to BMP-2 in solution.

Importantly, the bioactivity of the dry BMP-2 loaded films remained at a similar level to that of hydrated films, which confirmed the protective role of the film in the stabilization of the BMP-2 structural elements. These results appear highly promising for future applications of these films as coatings of biomedical materials, to sequester proteins and to deliver them locally, while preserving their bioactivity and secondary structure. It would be interesting to investigate whether similar mechanisms may take place for other types of growth factors that have been successfully adsorbed on PEMs films and whose bioactivity was proved. ${ }^{45}$

\section{ASSOCIATED CONTENT}

S Supporting Information

Structure of cross-linked (PLL/HA) films in hydrated and dry states, FTIR control experiments on the effect of $\mathrm{pH}$ changes ( $\mathrm{pH} 7.4$ to $\mathrm{pH} 3$ and the reverse) on the film spectra obtained in the hydrated state and in the dry state, and stability of BMP2 loaded (PLL/HA) 12 films over a 1 month period. This material is available free of charge via the Internet at http:// pubs.acs.org.

\section{AUTHOR INFORMATION}

\section{Corresponding Author}

*E-mail: catherine.picart@grenoble-inp.fr; phone: +33(0)4 56 5293 11; fax: +33(0)456529301.

\section{Notes}

The authors declare no competing financial interest.

\section{ACKNOWLEDGMENTS}

This work was supported by the French Ministry of Research through an ANR-EmergenceBIO grant (ANR-09-EBIO-01201), by the European Commission (FP7 program) via a European Research Council starting grant (BIOMIM, GA 259370), and by GRAVIT (081012_FIBIOS). C.P. is grafetul to IUF for financial support.

\section{REFERENCES}

(1) Lutolf, M. P.; Hubbell, J. A. Nat. Biotechnol. 2005, 23, 47-55. Hubbell, J. A. Curr. Opin. Biotechnol. 2004, 15, 381-2.

(2) Shimer, A. L.; Oner, F. C.; Vaccaro, A. R. Injury 2009, 40 (Suppl 3), S32-8.

(3) Lee, K.; Silva, E. A.; Mooney, D. J. J. R. Soc. Interface 2011, 8, $153-70$.

(4) Hynes, R. O. Science 2009, 326, 1216-9.

(5) Haidar, Z. S.; Hamdy, R. C.; Tabrizian, M. Biotechnol. Lett. 2009, $31,1817-24$.

(6) Obradovic Wagner, D.; Sieber, C.; Bhushan, R.; Borgermann, J. H.; Graf, D.; Knaus, P. Sci. Signaling 2010, 3, mr1.

(7) Reddi, A. H.; Reddi, A. Cytokine Growth Factor Rev. 2009, 20, $341-2$.

(8) Rickard, D. J.; Sullivan, T. A.; Shenker, B. J.; Leboy, P. S.; Kazhdan, I. Dev. Biol. 1994, 161, 218-28.

(9) Schmidmaier, G.; Schwabe, P.; Strobel, C.; Wildemann, B. Inj. Int. J. Care Inj. 2008, 39 (Suppl 2), S37-43.

(10) Carragee, E. J.; Hurwitz, E. L.; Weiner, B. K. Spine. J. 2011, 11, 471-91.

(11) Haidar, Z. S.; Hamdy, R. C.; Tabrizian, M. Biotechnol. Lett. 2009, 31, 1825-35.

(12) Phillippi, J. A.; Miller, E.; Weiss, L.; Huard, J.; Waggoner, A.; Campbell, P. Stem Cells 2008, 26, 127-34.

(13) Patterson, J.; Siew, R.; Herring, S. W.; Lin, A. S.; Guldberg, R.; Stayton, P. S. Biomaterials 2010, 31, 6772-81.

(14) Dierich, A.; Le Guen, E.; Messaddeq, N.; Stoltz, S.; Netter, P.; Schaaf, P.; Voegel, J.-C.; Benkirane-Jessel, N. Adv. Mater. 2007, 19, 693-7.

(15) Crouzier, T.; Ren, K.; Nicolas, C.; Roy, C.; Picart, C. Small 2009, 5, 598-608.

(16) Wang, W. Int. J. Pharm. 2005, 289, 1-30. 
(17) Oliveira, A. F.; Gemming, S.; Seifert, G. J. Phys. Chem. B 2011, $115,1122-30$.

(18) Schwartz, D.; Sofia, S.; Friess, W. Eur. J. Pharm. Biopharm. 2006, 63, 241-8.

(19) Schwartz, D.; Sofia, S.; Friess, W. Eur. J. Pharm. Biopharm. 2006, 63, 241-8.

(20) Hillger, F.; Herr, G.; Rudolph, R.; Schwarz, E. J. Biol. Chem. 2005, 280, 14974-80.

(21) Crouzier, T.; Fourel, L.; Boudou, T.; Albiges-Rizo, C.; Picart, C. Adv. Mater. 2011, 23, H111-8.

(22) Izumrudov, V. A.; Kharlampieva, E.; Sukhishvili, S. A. Biomacromolecules 2005, 6, 1782-8.

(23) Bi, X.; Taneva, S.; Keough, K. M.; Mendelsohn, R; Flach, C. R. Biochemistry 2001, 40, 13659-69.

(24) Zhang, X.; Ge, N.; Keiderling, T. A. Biochemistry 2007, 46, 5252-60. Pal, P.; Kamilya, T.; Mahato, M.; Talapatra, G. B. Colloids Surf., B: Biointerfaces 2009, 73, 122-31.

(25) Dong, A.; Huang, P.; Caughey, W. S. Biochemistry 1990, 29, 3303-8. Schwinte, P.; Ball, V.; Szalontai, B.; Haikel, Y.; Voegel, J. C.; Schaaf, P. Biomacromolecules 2002, 3, 1135-43.

(26) Boulmedais, F.; Schwinté, P.; Gergely, C.; Voegel, J. C.; Schaaf, P. Langmuir 2002, 18, 4523-5.

(27) Schwinte, P.; Voegel, J. C.; Picart, C.; Haikel, Y.; Schaaf, P.; Szalontai, B. J. Phys. Chem. B 2001, 105, 11906-11916.

(28) Jiang, Y.; Li, C.; Nguyen, X.; Muzammil, S.; Towers, E.; Gabrielson, J.; Narhi, L. J. Pharm. Sci. 2011, 100, 4631-41.

(29) Hasegawa, T.; Taniguchi, K.; Sato, Y. Vib. Spectrosc. 2009, 51, 76-79.

(30) Barth, A.; Zscherp, C. Q. Rev. Biophys. 2002, 35, 369-430.

(31) Ulloa, R. M.; Muschietti, J. P.; Veron, M.; Torres, H. N.; TellezInon, M. T. Mol. Biochem. Parasitol. 1995, 70, 119-29.

(32) Abbatiello, S. E.; Porter, T. J. Protein Science; poster presentation, Protein Society Meeting, Boston, MA, 1997; p 99.

(33) Hauburger, A.; von Einem, S.; Schwaerzer, G. K.; Buttstedt, A.; Zebisch, M.; Schraml, M.; Hortschansky, P.; Knaus, P.; Schwarz, E. FEBS J. 2009, 276, 6386-98.

(34) Schneider, A.; Francius, G.; Obeid, R.; Schwinte, P.; Hemmerle, J.; Frisch, B.; Schaaf, P.; Voegel, J. C.; Senger, B.; Picart, C. Langmuir 2006, 22, 1193-200.

(35) Shen, L.; Chaudouet, P.; Ji, J.; Picart, C. Biomacromolecules 2011, $12,1322-31$.

(36) Friess, W.; Uludag, H.; Foskett, S.; Biron, R.; Sargeant, C. Int. J. Pharm. 1999, 187, 91-9.

(37) Uludag, H.; D’Augusta, D.; Golden, J.; Li, J.; Timony, G.; Riedel, R.; Wozney, J. M. J. Biomed. Mater. Res. 2000, 50, 227-38.

(38) Scheufler, C.; Sebald, W.; Hulsmeyer, M. J. Mol. Biol. 1999, 287, 103-15.

(39) Flach, C. R.; Brauner, J. W.; Taylor, J. W.; Baldwin, R. C.; Mendelsohn, R. Biophys. J. 1994, 67, 402-10.

(40) Crouzier, T.; Picart, C. Biomacromolecules 2009, 10, 433-42.

(41) Prestrelski, S. J.; Tedeschi, N.; Arakawa, T.; Carpenter, J. F. Biophys. J. 1993, 65, 661-71.

(42) Katagiri, T.; Yamaguchi, A.; Komaki, M.; Abe, E.; Takahashi, N.; Ikeda, T.; Rosen, V.; Wozney, J. M.; Fujisawa-Sehara, A.; Suda, T. J. Cell. Biol. 1994, 127, 1755-66.

(43) Haxaire, K.; Marechal, Y.; Milas, M.; Rinaudo, M. Biopolymers 2003, 72, 10-20.

(44) Wei, W. Int. J. Pharm. 2005, 289, 1-30.

(45) Muller, S.; Koenig, G.; Charpiot, A.; Debry, C.; Voegel, J.; Lavalle, P.; Vautier, D. Adv. Funct. Mater. 2008, 18, 1767-1775. Vodouhe, C.; Schmittbuhl, M.; Boulmedais, F.; Bagnard, D.; Vautier, D.; Schaaf, P.; Egles, C.; Voegel, J. C.; Ogier, J. Biomaterials 2005, 26, 545-554. 